2 Kurukulaaratchy RJ, Fenn MH, Waterhouse LM, Matthews SM, Holgate ST, Arshad SH. Characterization of wheezing phenotypes in the first 10 years of life. Clin Exp Allergy 2003; 33: 573-578.

3 Kurukulaaratchy RJ, Matthews S, Holgate ST, Arshad SH. Predicting persistent disease among children who wheeze during early life. Eur Respir J 2003; 22: 767-771.

4 Kurukulaaratchy RJ, Matthews S, Arshad SH. Does environment mediate earlier onset of the persistent childhood asthma phenotype? Pediatrics 2004; 113: 345-350.

5 Arshad SH, Hide DW. Effects of environmental factors on the development of allergic disorders in infancy. J Allergy Clin Immunol 1992; 90: 235-241.
6 Sadeghnejad A, Karmaus W, Arshad SH Kurukulaaratchy R, Huebner M, Ewart S. IL-13 gene polymorphisms modify the effect of exposure to tobacco smoke on persistent wheeze and asthma of childhood. A longitudinal study. Respir Res 2008; 9: 2.

7 Bottema RWB, Reijmerink NE, Kerkhof M, et al. Interleukin 13, CD14, pet and tobacco smoke influence atopy in three Dutch cohorts: the allergenic study. Eur Respir J 2008; 32: 593-602.

8 Conan Doyle A. The Return of Sherlock Holmes. London, George Newnes Ltd, 1905.

DOI: $10.1183 / 09031936.00149408$

\title{
Pre-immigration screening for pulmonary tuberculosis
}

\section{From the authors:}

The authors thank BHUNIYA [1] for his interesting comments on our article published in the European Respiratory Journal (ERJ) [2]. Tuberculosis (TB) screening policies are influenced by the structure of the national TB programme, the existing financial resources, the expertise of available professionals and the sense of apprehension expressed by the local population in the host country.

The aim of our study was to evaluate the unique screening process performed in Ethiopian immigrants arriving in Israel, and to share our experience with the ERJ's readers.

The tuberculin skin test (TST) is considered the preferred method for screening latent TB infection (LTBI) in immigrants originating from countries with high rates of TB [3-5]. This method can potentially detect all patients with LTBI [6] in a simple, inexpensive and sensitive fashion. The merits of this instrument are increased when the physician considers the patients' age, previous TB exposure and past BCG vaccination in addition to the TST results. The interpretation of the TST using those additional data increases the specificity of the test [7].

Chest radiography (CXR) is considered the preferred test for the immediate detection of radiological findings suggestive of active pulmonary TB (PTB) [8]. The reliability of CXR depends on the experience and interpretative skills of the reader [9], knowledge of the sex and HIV status of the patient [10] and the quality of the film. In addition, it can detect abnormalities compatible with previous TB infection. Therefore, some experts recommend this instrument for screening immigrants originating from high-TB-incidence countries for LTBI [11].

As for the interpretations of the CXR, readers should be aware that the same team consists of three radiologists, who are working in the same hospital and have performed this task for nearly $7 \mathrm{yrs}$, while decreasing their inter-observer variability. As for the individual risk of radiation while performing CXR, the literature does not see or prove risk to the diagnosed patient if it is performed within the indication of screening or future treatment. It is also known that CXR is not commonly performed in Ethiopia for this low-income and rural people, and the clinical diagnosis prevails. Thus, in most cases, this is the immigrant's first life-time exposure to radiography.

Most industrialised countries use a combination of CXR and TST to screen immigrants originating from high-TB-incidence countries [12-15]. The Israeli TB screening policy in Addis Ababa, Ethiopia includes both of these methods for the detection of LTBI and PTB. The Israeli screening process employs additional measures to support those instruments and to augment the validity of the entire process, such as physical examination and symptom questionnaire for each immigrant. In addition, the follow-up is resumed while the immigrants are housed in the designated absorption centres and are tested for the second-step TST. Medical follow-up is provided by a nurse at these centres during the first few years of acclimatisation in Israel.

HIV tests are performed for the Ethiopian immigrants only after arrival in Israel. Israeli immigration laws are unique, and allow immigrants of Jewish descent to be naturalised in Israel upon arrival, and provided with all social benefits including national health insurance. Therefore, HIV-infected immigrants are entitled to follow-up and therapy when indicated. The right to immigrate to Israel is unrelated to the health status of the immigrants, and there is high social sensitivity in Israel to any bureaucratic barriers for the homecoming of Jews. However, because HIV may stigmatise this a priori marginalised population of immigrants, we prefer to perform HIV testing in Israel in a non-coercive manner only after arrival. This way, the immigrants are reassured that no pre-arrival medical condition deprives them of the anticipated homecoming. We do, however, test for TB prior to immigration, as the mycobacterium may infect otherwise healthy individuals during air travel to Israel and immediately thereafter. The results of TB screening performed previously in Ethiopia are compared with the HIV tests conducted in Israel to compose a comprehensive evaluation of each individual.

Finally, isoniazid resistance was diagnosed in less than $5 \%$ of the PTB immigrants. Therefore, we assume that the relatively low isoniazid resistance and the relatively low risk for sideeffects of the therapy, as well as the high cost-effectiveness of 
the current regimen, are superior in comparison to alternative preventive therapy options. Nevertheless, consistent evaluation of drug sensitivity tests is imperative in an ongoing evaluation of this decision.

In conclusion, our study is based on valid material and on actual circumstances, and its outcome can provide some evidence to yield of screening of potential immigrants from Ethiopia, and hopefully from other African countries.

\section{Z. Mor*, Y. Lerman ${ }^{\#,+}$ and A. Leventhal ${ }^{*,+}$}

${ }^{*}$ Public Health Services, Ministry of Health, ${ }^{+}$Braun School of Public Health of Hadassah and the Hebrew University, Jerusalem, "Preventive Medicine Dept, Clalit Health Services, and School of Public Health, Sackler Faculty of Medicine, Tel Aviv University, Tel Aviv, Israel.

\section{STATEMENT OF INTEREST}

None declared.

\section{REFERENCES}

1 Bhuniya S. Pre-immigration screening for pulmonary tuberculosis: the unanswered questions. Eur Respir J 2009; 33: 221-222.

2 Mor Z, Lerman Y, Leventhal A. Pre-immigration screening process and pulmonary tuberculosis among Ethiopian migrants in Israel. Eur Respir J 2008; 32: 413-418.

3 Institute of Medicine. Ending neglect: the elimination of tuberculosis in the United States. Washington, DC, National Academies Press, 2000; pp. 87-97.

4 Centers for Disease Control and Prevention, Screening for tuberculosis and tuberculosis infection in high-risk populations: recommendations of the Advisory Council for the Elimination of Tuberculosis. MMWR 1995; 44: 18-34.

5 Broekmans JF, Migliori GB, Rieder HL, et al. World Health Organization, International Union Against Tuberculosis and Lung Disease, and Royal Netherlands Tuberculosis Association Working Group. European framework for tuberculosis control and elimination in countries with a low incidence. Recommendations of the World Health Organization (WHO), International Union Against Tuberculosis and Lung Disease (IUATLD) and Royal
Netherlands Tuberculosis Association (KNCV) Working Group. Eur Respir J 2002; 19: 765-775.

6 Menzies D. Screening immigrants to Canada for tuberculosis: chest radiography or tuberculin skin testing? CMAJ 2003; 169: 1035-1036.

7 American Thoracic Society, Centers for Disease Control Treatment of tuberculosis and tuberculosis infection in adults and children. Am J Respir Crit Care Med 1994; 149: 1359-1374.

8 Marhez C, Bangala Y, Bady P, Zellweger JP. Active screening for pulmonary tuberculosis by chest $\mathrm{X}$-ray among immigrants at the Swiss border. Swiss Med Wkly 2007; 137: 649-654.

9 Nakamura K, Ohmi A, Kurihara T, Suzuki S, Tadera M. Studies on the diagnosis value of $70 \mathrm{~mm}$ radiophotograms by mirror camera and reading ability of physicians. Kekkaku 1970; 45: 121-128.

10 van Cleeff MRA, Kivihya-Ngugga LE, Meme $H$, Odhiambo JA, Klaster PR. The role and performance of chest X-ray for the diagnosis of tuberculosis: a cost effectiveness analysis in Nairobi, Kenya. BMC Infect Dis 2005; 5: 111.

11 Menzies D. Chest radiography versus tuberculin skin testing for tuberculosis screening of immigrants to Canada. www.cmaj.ca/cgi/content/full/169/10/1035/ DC1. Date last accessed: September 29, 2008.

12 Coker RJ, Bell A, Pitman R, Hayward A, Watson J. Screening programmes to tuberculosis in new entrants across Europe. Int J Tuberc Lung Dis 2004; 8: 1022-1026.

13 Saraiya M, Cookson ST, Tribble $\mathrm{P}$, et al. Tuberculosis screening among foreign born persons applying for permanent US residence. Am J Public Health 2002; 92: 826-826.

14 Pang SC, Harrison RH, Brearley J, Jegathesan V, Clayton AS. Tuberculosis surveillance in immigrants through health undertaking in western Australia. Int $J$ Tuberc Lung Dis 2000; 4: 232-236.

15 Richards B, Kozak R, Brassard P, Menzies D, Scwartzman K. Tuberculosis surveillance among new immigrants in Montreal. Int J Tuberc Lung Dis 2005; 9: 858-864.

\section{Left ventricular dysfunction in patients with interstitial lung diseases}

\section{To the Editors:}

The paper by PAPADOPOULOS et al. [1] describes the failure of systolic left ventricular (LV) function in patients with idiopathic lung fibrosis (IPF).

Not much is known about LV systolic and diastolic function failure in IPF patients or its influence on rates of survival. In 1998, VizZA et al. [2] examined a large group of patients with advanced lung diseases and estimated that $6 \%$ of them had LV failure, in particular patients with primary pulmonary hypertension and Eisenmenger's syndrome. However, in a patient group with interstitial lung diseases (ILD) the proportion was lower and reached $3.6 \%$.

In 2007, we studied LV systolic function in 18 patients with lung fibrosis and heavy respiratory insufficiency [3]. The patients 